\title{
Corneal vascularization induced experimentally with corneal extracts
}

\author{
P. J. FOLGA*
}

Department of Physiology, Institute of Ophthalmology, University of London

Corneal oedema with its associated stromal lamellar or fibrillar separation has been proposed as the essential stimulus for corneal vascularization in disease (Cogan, 1949). This widely accepted theory was elaborated by Ashton and Cook (1953), who considered that, in addition, a chemical stimulus for vascularization was afforded by a state of "suboxidation" constantly present in corneal tissue. The literature concerning the stimulus for corneal invasion by vessels has been reviewed thoroughly by Ashton (1960).

An alternative theory, proposing the release by diseased corneal tissue of a chemical influence for vascular invasion or "vessel-stimulating factor", has been postulated (Campbell and Michaelson, I949; Maurice, Zauberman, and Michaelson, 1966), but direct evidence of the existence of this factor has not so far been obtained. The relevant arguments for and against it have been fully discussed by Ashton (1960) and Maurice and others (1966). The latter produced suggestive evidence by implanting fine tubes into the corneal stroma radially disposed to a thermal lesion near the corneal centre. Vessels grew from the corneal periphery into five out of nine tubes open at both ends, but failed to do so in nine tubes of which the central ends were sealed. Diffusion of a chemical substance from the lesion was invoked to explain these findings.

If a chemical stimulus for invasion of the cornea by vessels is released in pathological states by damaged or diseased corneal tissue, it might be possible experimentally to injure the cornea in a way that would be expected to lead to vascularization, and then to excise, homogenize, and extract that cornea, and to induce vascularization by applying the extract by a suitable means to a normal cornea.

This principle was investigated in the adult Dutch rabbit in the following experiments.

\section{Materials and methods}

PREPARATION OF GORNEAL EXTRACT

Excised corneae were homogenized in a glass pestle and mortar by grinding in 0.9 per cent. saline ( $2 \mathrm{ml}$. per cornea) with capillary tubing fragments until a homogeneous milky fluid was obtained (Graymore and McCormick, 1966). This was centrifuged for 20 min. at 4,500 r.p.m. and the slightly opalescent supernatant fluid was stored at $-20^{\circ} \mathrm{C}$. in an airtight glass container. Instruments and glassware were sterilized before use.

APPLICATION OF EXTRACT

Adult Dutch rabbits were anaesthetized with intravenous nembutal for one hour daily on six successive days. On the first day, after the instillation of one drop of amethocaine I per cent., the corneal 
epithelium was removed by scraping gently with a Swann Morton scalpel (No. 15 blade) the entire corneal surface with the exception of the macroscopically identifiable limbal zone. The globe was steadied with a squint hook placed in the conjunctival fornix and the lids were separated by a speculum. After irrigation with 0.9 per cent. saline to remove epithelial debris, the speculum was removed and a Perspex scleral contact lens placed in the conjunctival sac. The central portion of these lenses had each been drilled to receive a perspex tube of $4 \mathrm{~mm}$. bore, $\mathrm{I} \cdot 5 \mathrm{~cm}$. long, which was cemented to the hole at right angles to the plane of the rim of the lens. With the rabbit lying on its side and the experimental eye uppermost, this tube was directed vertically and through it, by means of a Pasteur pipette, the space between the scleral lens and anterior surface of the eye (demonstrable with a slit beam) could be filled with extract or saline. Each application was made for one hour under maintained anaesthesia on six successive days. Aureomycin ointment was placed in the conjunctival sac after each application. On the fifth day, immediately before the fifth application, the loosely adherent, regenerating corneal epithelium was removed with a cotton wool swab on a wooden applicator.

\section{(1) Experiments with an extract of thermally-injured corneae}

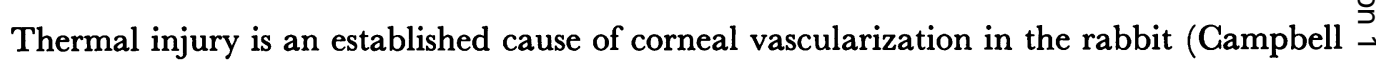
and Michaelson, 1949). This was chosen to avoid contamination of the extract with the $\underset{\mathbb{D}}{\overparen{D}}$ alternative agents providing a vascularizing stimulus, e.g. irritant fluids, alloxan, or bacteria. Diathermy lesions (35-40 milliamps $\times$ approx. I sec.) were applied with a fine electrode to both corneae of five adult Dutch rabbits anaesthetised with intravenous nembutal, producing multiple closely-spaced white spots 0.5 to $1 \mathrm{~mm}$. across (epithelial and stromal) over the entire cornea, each separated from the nearest by approximately twice the width of a lesion. A stronger current (6o milliamps $\times$ approx. I sec.) was used to produce a circular area approximately $4 \mathrm{~mm}$. across and adjacent to the limbus of contiguous and deeper lesions with slight charring. After I hr of sustained anaesthesia the animals were killed by injection of an overdose of anaesthetic, the corneae were excised and a pooled extract was prepared from them as described. The $\mathrm{pH}$ of the $\overrightarrow{\overrightarrow{0}}$ extract was between $7 \cdot 0$ and $7 \cdot 2$. The osmolarity both of the extract and of the saline with which it was prepared was measured by a depression of freezing-point method. The values differed by less than 3 per cent., the experimental error of the method of determination. This finding suggests that there was little difference between the oxygen content of the extract and that of saline, so that the test and control corneae were exposed to similar concentrations of oxygen (Stoddard, 1927).

This extract was applied to one eye of each of six adult Dutch rabbits on six successive days as described earlier. Six control animals, in which $0 \cdot 9$ per cent. saline was used instead of corneal extract, were treated in an otherwise identical fashion.

\section{RESULTS}

Both test and control eyes showed stromal and, where it was regenerating, epithelial oedema consistent with epithelial removal (Maurice and Giardini, 195I). Limbal hyperaemia was from the outset more marked in the test than in the control eyes, and in some of the former progressive, while tending to diminish as epithelium regenerated in the ? controls. Invasion of the cornea from the perilimbal plexus by radially-disposed vessels occurred in all the test animals. These vessels appeared between the third and sixth days, continued to grow until approximately the tenth, then regressed abruptly. Regression was virtually complete by the fourteenth day. They were scattered round the corneal 
periphery, reached a maximum length of approximately $3 \mathrm{~mm}$., were mainly in the superficial stroma but occasionally deeper, and formed loops with adjacent invading twigs shortly after their appearance (Fig. I).

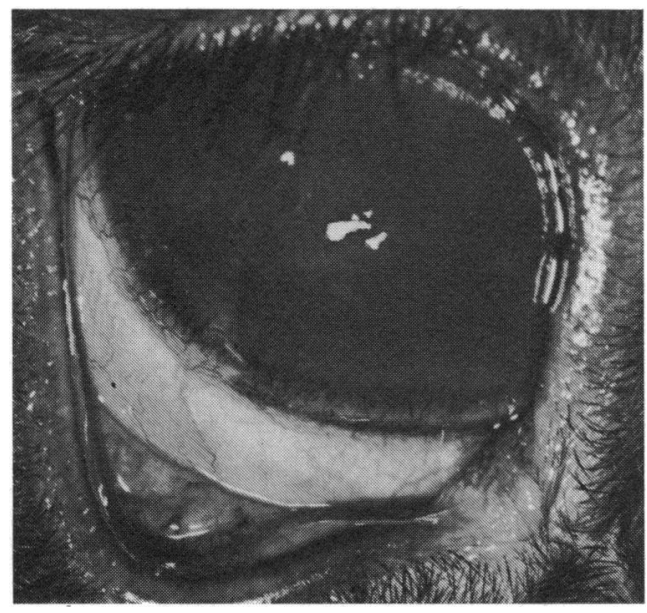

FIG. I Test eye (experiment I), roth day

No vascularization was seen in the corneae of the control animals treated with $0 \cdot 9$ per cent. saline.

\section{(2) Experiments with an extract of corneae not receiving a thermal injury}

The vascularization observed in the preceding experiment could be due either to the specific products of thermal injury or to the products of autolysis or loss of enzymic regulation in corneal tissue disorganized by grinding. The above experiment was repeated to differentiate these possibilities using an extract, prepared in the same way, of corneae not thermally injured and excised immediately after the death of the rabbits from an overdose of intravenous nembutal. This was applied in identical fashion to one eye of each of six animals.

\section{RESULTS}

Vascularization was observed in four of the six corneae. Vessels appeared on the sixth and seventh days, were less numerous than in the preceding experiment, reached a maximum (not more than $2 \mathrm{~mm}$.) by the Ioth to 12 th days, and then regressed rapidly.

\section{(3) Experiments with autogenous corneal extract}

The vascularization observed so far might result merely from repeated exposure of the cornea to non-autologous protein (i.e. comparable to that associated with a von Szily phenomenon). Furthermore, the extracts might induce vascularization, although possibly by chemical means, merely by producing greater corneal swelling and lamellar separation than any caused by saline. These possibilities were investigated in the following manner:

(i) One eye of each of twelve adult Dutch rabbits was enucleated, the socket was dusted with "Polybactrin" powder, and an individual extract of each cornea (not thermally injured) was pre- 
pared. After 3 days applications of that extract to the remaining eye of the corresponding animal were begun. The procedure was identical to that already described except in the following respects:

(a) Only five instead of six daily applications were made because of the small amount of extract available.

(b) Epithelium was therefore removed for the second time on the fourth and not on the fifth day, so that two applications followed the second removal of epithelium, as in earlier experiments.

Controls were repeated (no enucleation was performed, however, in these animals) using 0.9 per cent. saline instead of corneal extract.

(ii) Measurements of axial corneal thickness (Maurice and Giardini, 1951) were made repeatedly before anaesthesia in test and control eyes (before the removal of epithelium and before daily applications) until the thickness returned in each case to its initial level.

\section{RESULTS}

Seven of the twelve test animals showed a corneal vascular response, similar to that previously seen, starting between the fifth and seventh days and beginning to regress rapidly between the ninth and eleventh days. It is of interest that four of these animals showed a response comparable in degree to that seen in Experiment $\mathrm{I}$. No vascularization occurred in the twelve control corneae.

No relationship was apparent between the degree of corneal swelling and vascularization. The greatest swelling in all 24 animals occurred in one of the controls and, within the test group, one cornea which was not invaded by vessels demonstrated greater overall axial swelling than one which vascularized (Fig. 2). The corneal thickness returned to its initial level between the seventh and tenth days, usually on the eighth. However the appearance on slit-lamp examination of slight epithelial and anterior stromal oedema often persisted for a day or two later.

\section{Discussion}

Of the corneae to which 0.9 per cent. saline was applied ( 18 in all) none vascularized. All corneae (6) vascularized in the group treated with the saline extract of thermally-injured corneae (Experiment I $\mathrm{P}<0.05$ ); four corneae vascularized of the six treated with extract of corneae which had not been injured thermally (Experiment 2); seven corneae vascularized of the twelve treated with an extract of the animal's own other cornea (Experiment $3 \quad \mathrm{P}<0 \cdot 0 \mathrm{r}$ ). Although the incidence of vascularization varied in the three experiments, the number of observations made does not permit a conclusion to be drawn regarding the relative potency of the extracts.

These observations suggest the presence in the extracts of a vessel-stimulating substance or substances for the following reasons:

(i) $\mathrm{pH}$, osmolarity, and (presumptively) oxygen content of extract and of saline were closely similar;

(ii) measurements of corneal swelling (in Experiment 3) did not disclose a relationship between the degree of swelling and either the presence or absence of vascularization;

(iii) corneal vascularization evidently did not result merely from the presence in the extracts either of specific products of thermal injury or of non-autologous protein.

It is concluded that in corneal tissue vessel-stimulating substances can occur as a result of autolysis or tissue disorganization. 


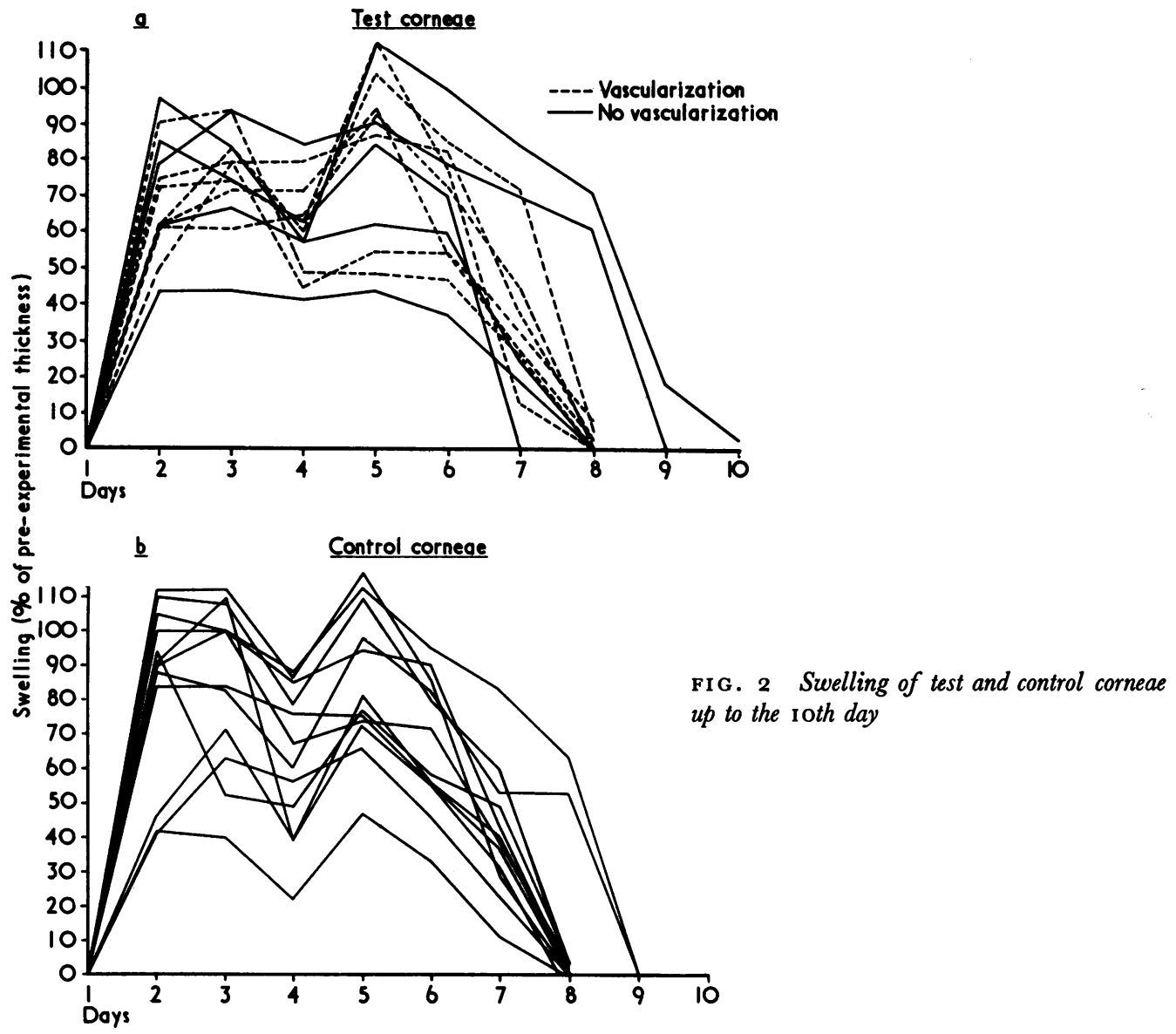

In a number of animals it was evident that the daily progress of the invading vessels was interrupted abruptly on approximately the tenth day by the onset of an equally rapid regression. A possible interpretation of this observation is that the stimulus for their presence had rapidly disappeared at this time; that is that the vessel-stimulating substances had suddenly been either inactivated or eliminated from the cornea. Several hypothetical mechanisms can be advanced for the latter alternative and include the process of deturgescence. The following observation may be relevant to this possibility: the onset of regression of vessels frequently coincided with the return of normal optical clarity of the cornea, presumably therefore as the regenerating epithelium recovered its normal function, permitting deturgescence.

Whatever the mechanism of its removal might be, the vascularizing influence seemed to disappear rapidly from the recipient cornea by some means. An analogy may be drawn between the experimental arrangement described and pathological processes of the cornea associated with vascularization and tissue damage. Experimentally the products of tissue disorganization were applied to the cornea; clinically they arise in situ. It may be postulated that vessel invasion occurs if the release of vessel-stimulating factor exceeds the corneal capacity for its elimination or inactivation.

It is generally accepted that oedema is necessary for corneal vascularization to occur (Ashton and Cook, 1953; Langham, 1953; Szeghy, 1960). Oedema was, in both test and 
control corneae, a consequence of the experimental procedure, and its extent was consistent with this, as already noted. The lack of relationship between axial swelling of the oedematous cornea and vascularization has also been noted. If the changes in axial thickness can be assumed to reflect changes in the overall corneal thickness in the experiments described, this lack of relationship indicates that the extracts did not exert a vascularizing influence by increasing the overall corneal swelling present.

\section{Summary}

Corneal vascularization was induced in adult Dutch rabbits by local application of saline, extracts of homogenized corneae, and corneae homogenized after thermal injury. The possible relevance of these findings to corneal disease is discussed.

It is concluded that disorganization of corneal tissue, with or without thermal injury, is associated with the release of a vessel-stimulating factor, apparently chemical in nature; the effect of the latter does not appear to be mediated by the production of corneal swelling.

I wish to thank Mr. R. Wilson, of the Contact Lens Department, Moorfields Eye Hospital, W.C.I., for making the scleral lenses; Mr. T. Tarrant, of the Institute of Ophthalmology, for his help with the illustrations; Miss C. Duncan, of the Medical Research Council Statistical Research Unit, for her advice; Dr. A. McCormick (at present), Department of Ophthalmology, University of British Columbia, Vancouver, for his assistance, and Dr. D. M. Maurice, Institute of Ophthalmology, for his advice and for kindly permitting me to use his apparatus.

\section{References}

Ashton, N. (I960) In "The Transparency of the Cornea", ed. S. Duke-Elder and E. S. Perkins p. 131. Blackwell, Oxford.

and cook, c. (1953) Brit. F. Ophthal., 37, 193

CAMPBell, F. W., and Michaelson, I. c. (1949) Ibid., 33, 248

COGAN, D. G. (1949) Arch. Ophthal. (Chicago), 4I, 406

GRAYMORE, C. N., and MCCORMICK, A. (1966) Exp. Eye Res., 5, 315

LANGham, M. E. (1953) Brit. F. Ophthal., 37, 2 I0

MAURICE, D. M., and GIARDINI, A. A. (I95I) Ibid., 35, 79I

—, zauberman, H., and michaelson, I. c. (1966) Exp. Eye Res., 5, i68

STODDARD, J. L. (1927) 7. biol. Chem., 71, 629

sZeGhy, G. (1960) v. Graefes Arch. Ophthal., 162, 2 I 5 